\title{
New mHealth application software based on myofunctional therapy applied to sleep- disordered breathing in non-compliant subjects
}

\author{
Carlos O'Connor Reina ${ }^{1,2^{*}}$ (D) Guillermo Plaza ${ }^{3,4}$, Jose Maria Ignacio-Garcia ${ }^{5,6}$, Peter Baptista Jardin? \\ Maria Teresa Garcia-Iriarte ${ }^{8}$, Juan Carlos Casado-Morente ${ }^{1,2}$, Eugenio De Vicente Gonzalez ${ }^{9}$ and \\ Agustin Rodriguez-Reina ${ }^{10}$
}

\begin{abstract}
Background: Myofunctional therapy (MT) is a therapeutic option with demonstrated efficacy for treating sleepdisordered breathing. We assessed the clinical application of a newly developed m-Health App, which aimed to allow patients with OSAHS (obstructive sleep apnea/hypopnea syndrome) to perform oropharyngeal exercises only by interacting with their smartphone without no other devices.

Methods: We offered to treat the OSAHS of 20 patients with the App for 90 sessions. Inclusion criteria were adult patients diagnosed with OSAHS who rejected, or could not tolerate or afford treatment for their OSAHS with other modalities. The App was used by 15 patients, while 5 were noncompliant and then were used as a control group. Polygraphy was performed at the beginning of the study, and after 90 sessions in the App group or after 3 months in the control group. Data for adherence to treatment, sex, body mass index (BMI), age, $\mathrm{O}_{2 \mathrm{MIN}}$ (oxygen minimal saturation) and apnea-hypopnea index (AHI) were collected for both groups.
\end{abstract}

Results: 15 (75\%) patients showed adherence to the treatment as measured as performing the exercises daily 5 days a week. In patients who performed the exercises, AHI decreased from $25.78 \pm 12.6$ to $14.1 \pm 7,7(p=0.002)$, Epworth changed from $18,2 \pm 1,98$ to $14,2 \pm 7,7(p=0,002)$ and $\left(\mathrm{O}_{2 \mathrm{MIN}}\right)$ changed from $84,87 \pm 7.02$ to $89,27 \pm 3,77$ $(p=0.0189)$. In the control group, there was no significant change.

Conclusions: To our knowledge, this is the first study reported where a mHealth App based on MT could be by itself a therapeutic option in selected patients with OSAHS.

Keywords: Myofunctional therapy, mHealth, Sleep apnea, Sleep-disordered breathing, Smartphone application

\section{Background}

Obstructive sleep apnea/hypopnea syndrome (OSAHS) has become one of the more serious health problems worldwide.(Mendes et al. 2014) Because of its relationship with obesity, its prevalence and incidence have been increasing and it is associated with severe

\footnotetext{
* Correspondence: coconnor@us.es

${ }^{1}$ Cohead Department Otorhinolaryngology, Hospital Quiron Salud Marbella, Avenida Severo Ochoa 22, 29603 Marbella, Spain

${ }^{2}$ Cohead Department of Otorhinolaryngology, Hospital Quiron Salud Campo de Gibraltar, Cádiz, Spain

Full list of author information is available at the end of the article
}

morbidities such as cardiovascular and cerebrovascular diseases. The classic treatment of this disease is based on dietary measures, losing weight, and exercise, and the use of a continuous positive airway pressure (CPAP) machine, a device that reduces collapsibility of the upper airway by emitting a flow of air. Other options are upper airway surgery, treating the obstacle of the airway or correcting the muscles that do not perform their function properly, and mandibular advancement devices (MAD), which protrudes the tongue forward to avoid it falling backward and collapsing the airway. The success rates and 
indications for all treatments depend on the adherence to the treatment and severity of the disease.(Mendes et al. 2014)

Myofunctional therapy (MT) has become one of the newest treatments for sleep-disordered breathing.(Camacho et al. 2015a) MT is based on daily exercises using oropharyngeal muscles in an attempt to strength them and facilitate opening of the airway. OSAHS originates from the lack of an optimal function of the dilator muscles of the airway. Therefore, MT is a therapy designed theoretically to deal with the underlying mechanism of this disease.(Korhan et al. 2015) MT is based on oropharyngeal exercises described by diagrams, videos, and instructions from a myofunctional therapist on a weekly basis. The patient is instructed to perform the exercises regularly, for at least 3 months, between 20 to 40 min daily. In some cases, patients perform exercises by themselves at home without substantial feedback and without giving an exact information to the therapist about their performance of the exercises.(O'Connor Reina et al. 2018)

Most existing mHealth Applications for OSAHS patient focus on diagnosis of snoring or OSAHS(Isetta et al. 2017), while a few are designed to promote adherence to treatment to CPAP(Camacho et al. 2015b). So far, to our knowledge, there are none focused in the treatment of OSAHS. However mobile technology could be especially valuable in treating OSAHS patient because of its potential to promote patient empowerment and selfmanagement(Iftikhar et al. 2017).

One of the best treatments for OSAHS is performing exercises and reducing weight.(KCC 2009) Because time is limited, we consider that there will be a greater probability of patients performing the exercises if they are able to do so while sitting comfortably and watching television. Therefore, we designed and developed a novel mHealth Application software (App) to promote oropharyngeal exercises while interacting with a smartphone. In this article, we introduce this APP and we present results regarding adherence to the App and its effectiveness in a group of patients with OSAHS.

\section{Methods}

\section{Application function, and availability}

This App is a smartphone App created in a collaboration between the Sleep Units of Hospital Quirónsalud Marbella and Campo de Gibraltar and their Engineering Informatics Departments and developed by Apnea Bye company. It was presented last November 2018.

We can think of this App as a portable gym with athletes instead of patients and trainers instead of therapists. The novelty of this App is that it is the first in the health-care market where the patient can interact directly with the smartphone without any other device, which provides feedback about the efficacy of the exercises performed and focused on sleep apnea disease. There are nine exercises based on MT that attempt to enhance the tonicity of the various muscles involved in the pathogenesis of OSAHS. Before every exercise, there is an animated gif demonstration that shows the patient how to perform the exercise (Figs. 1a-c). App's users can follow the development of their activity daily over time (Figs. 2a-c). At the conclusion of each exercise, the patient receives feedback about the success of their performance with a point score (Fig. 3). When the patient finishes the exercises, they are saved on networked online storage (in the Cloud) and a therapist (Fig. 4) can evaluate the performance of the exercises and achievements. A chat function is available where the patient can contact the therapist directly. There is a reminder every 5 days if the patient "forgets" to perform the exercises. The English-language version of this App is now available on Android and the iOS platform via Google Play and the App Store, respectively. Full information about the App is provided in a Web Page https://airwaygym.App/. Therapists can use it to enroll and follow up their patients.

This App was developed with the most cutting-edge technologies (e.g., Ionic, Angular provided by Google and TypeScript by Microsoft) and the most consolidated software languages (such as HTML5, CSS3, and PHP). The App takes advantage of 3D Touch technology, a capacity available in the latest Apple devices to accurately measure the pressure that is produced on the mobile screen. This App complies with regulation 2002/58/ CE and (UE) 2016/679 about Data protection.

The main objective of these exercises was to increase the tone of the extrinsic muscles of the tongue (genioglossus,hyoglossus,styloglossus and palatoglossus).

The exercises are based on those described by Guimaraes in 2009(KCC 2009), adapted to obtain a feedback with the phone.

Due to hygienical reasons we recommend to cover the screen with cling film or a hypoallergenic plastic wrap in all exercises.

Exercise 1. Snake With your elbows touching your body, hold the phone with both hands as you do when holding a mirror in front of your face.

Stick your tongue out and press the screen with it for $5 \mathrm{~s}$ and release. The tongue should not touch your teeth or lips.

Repeat the exercise 15 times. 


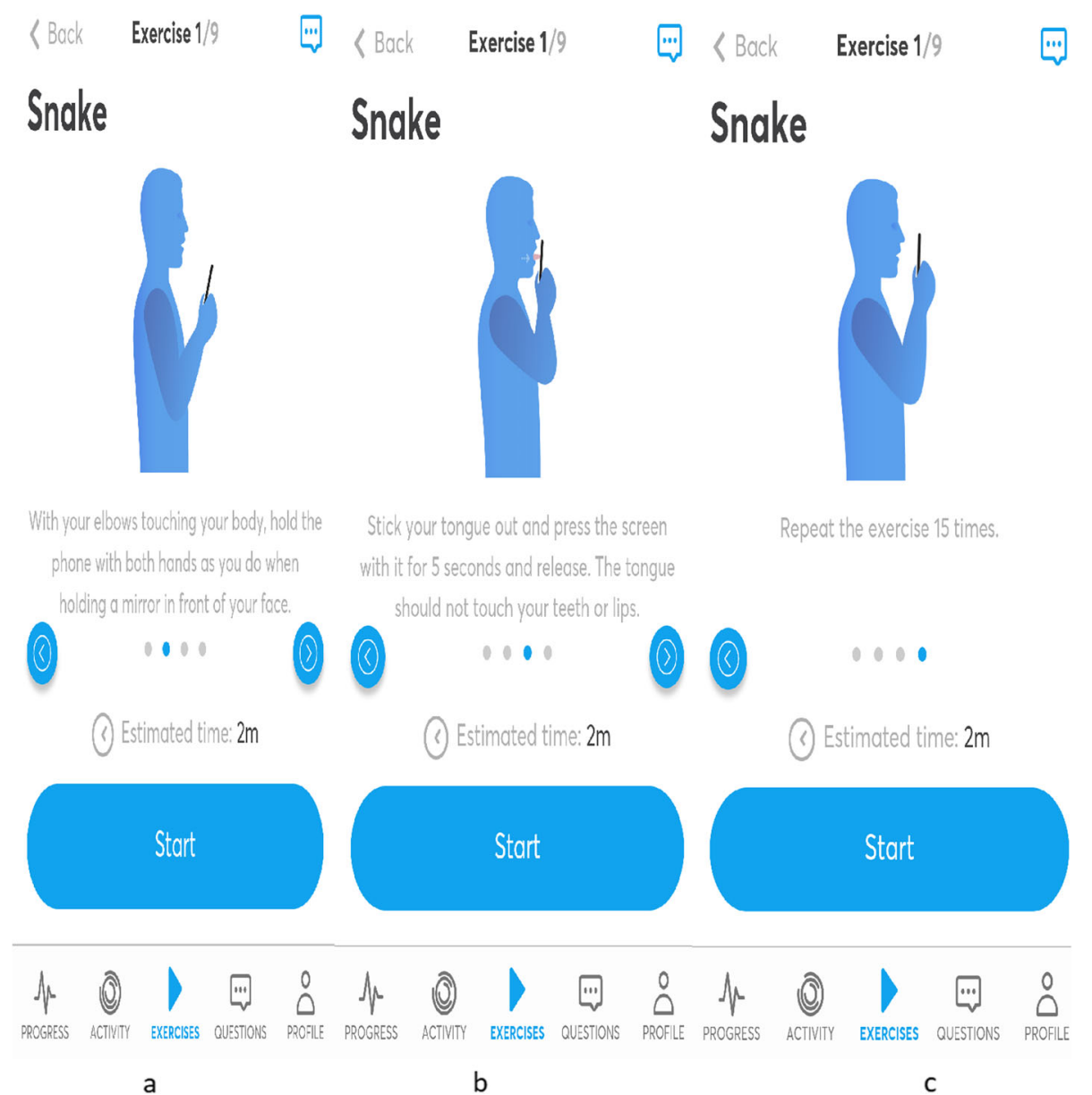

Fig. 1 a-c Exercise snake where patient should touch with his tongue the screen press it with suitable rhythm and strength and receive a positive sound of feedback.

Exercise 2. Pressure with your chin Fit your jaw 2 finger above the center of your phone. If you've got a beard place your finger between your phone and your jaw.

Open your mouth and keep pushing the screen for $5 \mathrm{~s}$, close your mouth and rest. While doing the exercise say $/ \mathrm{a} /$.

Repeat the exercise 15 times.

Exercise 3. Chameleon up Place the phone at a certain distance in front of you, as if it were a mirror.

Stick out your tongue and press on the square at the bottom. The tongue must not touch your teeth or lips.

Put your tongue up and keep the pressure on the screen $5 \mathrm{~s}$, close your mouth and rest.

Repeat the exercise 15 times.

Exercise 4. Chameleon down Due to hygienical reasons we recommend to cover the screen with cling film or a cleaning wipe.

Place the phone at a certain distance in front of you, as if it were a mirror.
Stick out your tongue and press on the square at the bottom. The tongue must not touch your teeth or lips.

Put your tongue down and keep pressing the screen for $5 \mathrm{~s}$, close your mouth and rest.

Repeat the exercise 15 times.

Exercise 5. Tongue left cheek Press with the tip of your tongue the inside of the left cheek. Allow the screen of your phone to touch gently your cheek.

Contract the muscles of your cheek while pushing with the tongue towards the cheek. Keep the pressure for $5 \mathrm{~s}$.

Repeat the exercise 15 times.

Exercise 6. Tongue right cheek Press with the tip of your tongue the inside of the right cheek. Allow the screen of your phone to touch gently your cheek.

Contract the muscles of your cheek while pushing with the tongue towards the cheek. Keep the pressure for $5 \mathrm{~s}$.

Repeat the exercise 15 times. 




Exercise 7. Pressure under chin Hold the phone with both hands with the screen facing up. If you've got a beard place your finger between your phone and your jaw.

Sitting upright put the phone under your chin so there is no contact with the chin.

Bend your head forward like you are going to drink from a cup and contact your chin on the phone.

Keep the contact and move your head from side to side during $10 \mathrm{~s}$ with your mouth closed. Lift your head and rest.

Repeat the exercise 15 times.

Exercise 8. Left mandibular pressure Bring the phone closer to the origin of the jaw on the left side. As if you were talking on the phone but with the screen to the outside.

Turn your jaw towards the phone and keep the pressure with your index finger on the screen for $5 \mathrm{~s}$. Say /i/ while doing it.

Release the pressure and rest. Repeat the process 15 times.

Exercise 9. Right mandibular pressure Bring the phone closer to the origin of the jaw on the right side. As if you were talking on the phone but with the screen to the outside.

Turn your jaw towards the phone and keep the pressure with your index finger on the screen for $5 \mathrm{~s}$. Say /i/ while doing it. 


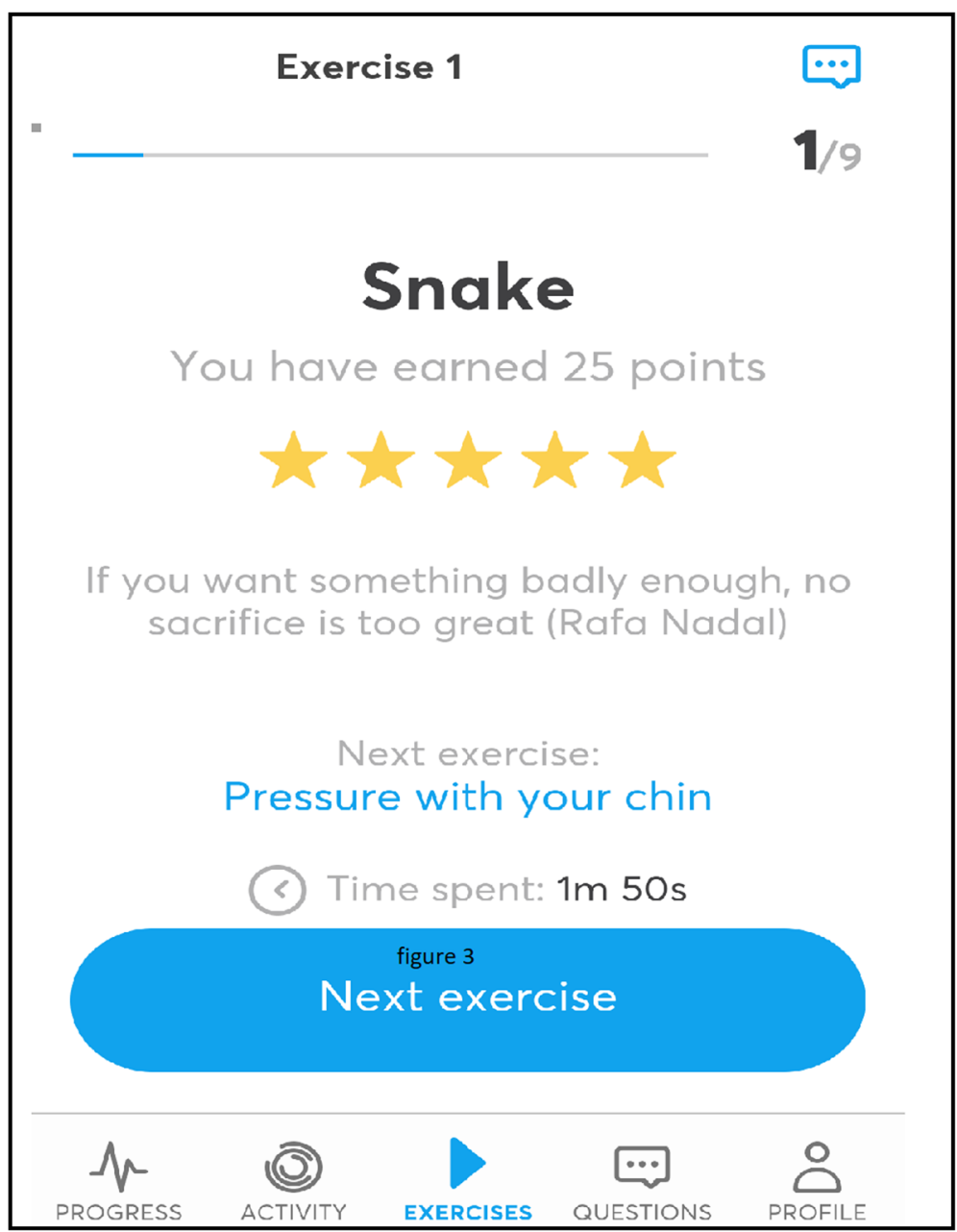

Fig. 3 Score achieved by patient after performing exercise

Release the pressure and rest. Repeat the process 15 times.

\section{Patients and methods}

This preliminary cross-sectional study Approved by the local Ethics Committee AWGAPN-2019-01. Study started January 2019 and all patients were studied in a comparable frame of time. The inclusion criteria were adult patients diagnosed with OSAHS by poligraphy and were non-compliant with any therapy and had a mobile. The exclusion criteria were patients with previous surgery in the UA, UA malformation (i.e., significant tongue tie). All patients gave informed consent.

Data including sex, age, body mass index (BMI), Epworth Sleepiness Scale (ESS), Minimal Oxigen Saturation $\left(\mathrm{O}_{2 \mathrm{MIN}}\right)$ and apnea-hypopnea index (AHI) obtained by poligraphy (Sleep \& Go, Sibelmed 2018) .

All sleep studies were manually interpreted by a sleep technician according to the standard criteria of the
American Academy of Sleep Medicine (AASM) Manual for the Scoring of Sleep and Associated Events and were reviewed by certified physicians (Adams et al., n.d.). Apnea was defined as an absence of airflow for a period lasting at least $10 \mathrm{~s}$ and hypopnea was defined as at least a 30\% reduction in airflow associated with a $4 \%$ or greater decrease in oxygen saturation. The AHI was defined as the number of episodes of apnea and hypopnea per hour of Total Sleep Time (American Academy of Sleep Medicine 2007). Finally, the adherence to treatment (those who performed the exercise at least 5 days a week) were collected. Then, patients were reevaluated after 90 sessions with the App with the same tests, or after 3 months in the control group by the same physician who blindly evaluated the results achieved from each group. All patients were instructed by the same therapist about the use of the App prior to enroll in the study. 


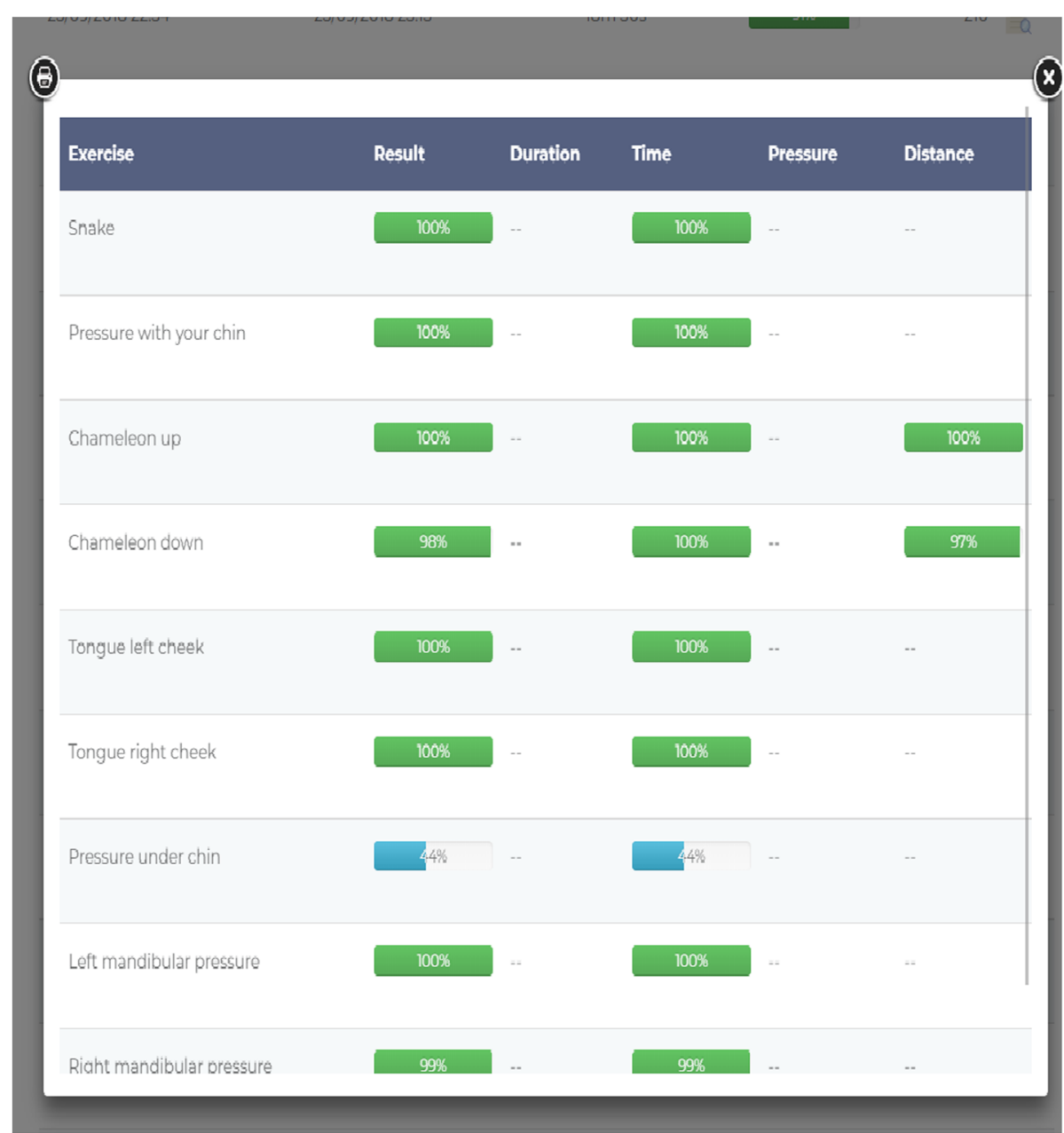

Fig. 4 Information obtained by Therapist about the accuracy and adherence of the performance of the exercises performed by patient

\section{Statistical analysis}

Quantitative variables were assessed by calculating the arithmetic mean and standard deviation and group of differences were assessed using a two-sample paired $t$ test, or using a Mann-Whitney rank sum test if the variable was not normally distributed. $P<0.05$ was considered significant. IBM SPSS Statistics for Windows software (version 20; IBM Corp, Armonk, NY, USA) was used for statistical analysis.

\section{Results}

We enrolled 20 consecutive patients diagnosed with OSAHS by physicians in our Sleep Unit. These patients had no treatment for their disease because 10 patients could not tolerate CPAP, 5 patients could not afford a MAD, and 5 patients could not tolerate CPAP or MAD, and rejected surgery. None had the option of a weekly visit to a myofunctional therapist because of geographical remoteness. The App was used by 15 patients who complied with its functions. Reasons for rejection of the App included problems with the temporomandibular joint (1 case), irritation of the tongue (1 case), and fatigue ( 3 cases).

The study population was mostly male, middle-aged, and overweight. Twelve male $(80 \%)$ and three women had adherence to the treatment, meanwhile three women $(60 \%)$ and two men (40\%) were non-compliant. The average aged of the compliant group were $36 \pm 13,5$, on the other hand, 53,2 \pm 7 years had the non-adherence group. There were no significant differences in the IMC of both groups $(24,8 \pm 2,8$ to $24,7 p=0,42,25,3 \pm 2,7$ to $26,3 \pm 3,3 \mathrm{p}=0,07$ respectively).

In the patients who performed the exercises the AHI decreased from $25.78 \pm 12.6$ to $14.1 \pm 7,7 \quad(p=$ 0.002) $\mathrm{t}=0,83$, Epworth changed from $18,2 \pm 1,98$ to $14,2 \pm 2,7(\mathrm{p}=0,002) \mathrm{t}=4,9$ and $\left(\mathrm{O}_{2 \mathrm{MIN}}\right)$ changed from $84,87 \pm 7.02$ to $89,27 \pm 3,77(p=0.0189) \quad \mathrm{t}=-2,7$. In the control group, there was no significant change in the AHI $(31.460 \pm 12.6$ to $32.90 \pm 12.8, p=0.4065) \mathrm{t}=$ 0,92 or $\left(\mathrm{O}_{2 \mathrm{MIN}}\right) 83,9 \pm 9$ to $82 \pm 9.4,(p=0.29) \mathrm{t}=1$ or Epworth $18,8 \pm 1,1$ to $19,4 \pm 1,95,(p=0.208) \mathrm{t}=-1,5$. 
The data are summarized in Tables 1 and 2 and Fig. 5.

\section{Discussion}

As the prevalence of obesity increases worldwide, OSAHS increases proportionally. We live in a world where effort and involvement are being forgotten. OSAHS treatments that aim for the comfort of the patient overlook that this disease is associated with sedentarism and passivity. Exercise is one of the best treatments for this disease(Iftikhar et al. 2017). Time is limited; therefore, this App was provided in an attempt to employ time effectively to resolve this disease. People spend a significant amount of time using their smartphones (Andrews et al. 2015) as they are an excellent companion and allow communication with social media but also the use of Apps may allow better use of a person limited time, in this case by the performance of MT exercise.

Understanding the reasons why some people with OSAHS have poor muscle effectiveness are incomplete. However, poor coordination of the neural drive to the various upper airway muscles during sleep, mechanically inefficient muscle fibre orientation (due to excess fat or muscle hypertrophy), or muscle fiber type changes resulting in greater propensity for fatigue could all be contributing factors. In general, people with OSAHS have poorer muscle effectiveness than non-OSAHS controls (Dotan et al. 2015).

Apps for smartphones and tablets have become indispensable, especially for young generations; however, increasing use of Apps in the middle-aged and elderly population is observed, thus arguing for a common use across generation borders. The estimated number of mobile devices will exceed 2.16 billion in 2016. Over 2.2 million Apps are available in the Google Play store, and about 1.8 million Apps are available in the Apple App Store ${ }^{\circ}$. Google and Apple distribute nearly 70,000 Apps each in the category Health and Fitness, and about 33, 000 and 46,000 each in medical Apps. The WHO defines these tools under the label "mHealth" or "eHealth" as "medical and public health practice supported by mobile devices, such as mobile phones, patient monitoring devices, personal digital assistants, and other wireless devices"(Vogel et al. 2017).

The results of the present study can be compared with other therapeutic options currently available.(Iftikhar et al. 2017) This App has the advantage of being affordable worldwide as a smartphone App and treats the etiology of the disease. For patients who cannot afford other treatment for their disease, this App presents an affordable option. While it may not substitute for established treatments, in those patients where there is no other

Table 1 All results obtained in both groups pre and post use the app

\begin{tabular}{|c|c|c|c|c|c|c|c|c|c|c|c|}
\hline Patient & Age & Sex & BMI (pre) & BMI (post) & AHI (pre) & $\mathrm{AHI}$ (post) & SatO2 Min & Sat O2Min (post) & ESS & ESS (POST) & $\mathrm{ADH}$ \\
\hline 1 & 23 & M & 24.2 & 25.1 & 17.8 & 14.2 & $83 \%$ & $85 \%$ & 16 & 14 & Y \\
\hline 2 & 19 & $\mathrm{~F}$ & 23.1 & 22.9 & 16.2 & 13.5 & $93 \%$ & $94 \%$ & 18 & 13 & Y \\
\hline 3 & 34 & M & 26.2 & 26 & 21.9 & 21 & $85 \%$ & $84 \%$ & 19 & 21 & Y \\
\hline 4 & 37 & M & 31.8 & 32 & 14.5 & 10.4 & $92 \%$ & $93 \%$ & 18 & 14 & Y \\
\hline 5 & 17 & M & 23.2 & 21.9 & 12.6 & 9.3 & $89 \%$ & $91 \%$ & 16 & 13 & Y \\
\hline 6 & 41 & $\mathrm{~F}$ & 21.3 & 20.9 & 13.2 & 12.1 & $92 \%$ & $92 \%$ & 17 & 16 & $N$ \\
\hline 7 & 28 & M & 26 & 26.2 & 15.7 & 9.1 & $91 \%$ & $90 \%$ & 17 & 12 & Y \\
\hline 8 & 32 & M & 24.3 & 24.1 & 28.8 & 17.7 & $86 \%$ & $90 \%$ & 19 & 13 & Y \\
\hline 9 & 29 & M & 21.9 & 21.5 & 15.4 & 12.3 & $88 \%$ & $88 \%$ & 18 & 15 & Y \\
\hline 10 & 25 & $M$ & 22.1 & 22 & 40.2 & 15,9 & $74 \%$ & $92 \%$ & 21 & 15 & Y \\
\hline 11 & 46 & $M$ & 25,5 & 24,5 & 42,2 & 24,5 & $69 \%$ & $86 \%$ & 20 & 14 & Y \\
\hline 12 & 50 & $M$ & 22,1 & 22 & 26,6 & 18,3 & $88 \%$ & $89 \%$ & 15 & 14 & Y \\
\hline 13 & 62 & $\mathrm{~F}$ & 25,5 & 24,5 & 17,8 & 3,1 & $91 \%$ & $93 \%$ & 16 & 16 & $Y$ \\
\hline 14 & 55 & $M$ & 24 & 24.2 & 24.1 & 4.5 & $87 \%$ & $92 \%$ & 19 & 10 & Y \\
\hline 15 & 43 & $M$ & 23.2 & 24.5 & 55 & 7 & $78 \%$ & $91 \%$ & 21 & 11 & $Y$ \\
\hline 16 & 47 & $\mathrm{~F}$ & 30 & 29.5 & 38 & 32 & $79 \%$ & $81 \%$ & 21 & 18 & Y \\
\hline 17 & 52 & $M$ & 28 & 29.9 & 24 & 31 & $87 \%$ & $86 \%$ & 19 & 20 & $N$ \\
\hline 18 & 56 & $M$ & 24.3 & 26.2 & 37 & 35.2 & $84 \%$ & $85 \%$ & 20 & 21 & $N$ \\
\hline 19 & 62 & $\mathrm{~F}$ & 25.3 & 26.7 & 39 & 41 & $81 \%$ & $80 \%$ & 19 & 20 & $N$ \\
\hline 20 & 55 & $\mathrm{~F}$ & 27.6 & 28.2 & 44.1 & 45.2 & $68 \%$ & $67 \%$ & 19 & 20 & $N$ \\
\hline
\end{tabular}


Table 2 Main grouped results

\begin{tabular}{|c|c|c|c|c|c|c|c|c|c|c|}
\hline PATIENT & SEX & AGE & BMI PRE & BMI POST & IAH PRE & IAH POST & $\begin{array}{l}\text { SAT O2 MIN } \\
\text { PRE }\end{array}$ & $\begin{array}{l}\text { SAT O2 MIN } \\
\text { POST }\end{array}$ & ESS PRE & ESS POST \\
\hline $\mathrm{AD}(15)$ & $\begin{array}{l}3 \mathrm{~F}, 12 \mathrm{M} \\
(80 \%)\end{array}$ & $\begin{array}{l}36 \pm 13 \\
5\end{array}$ & $\begin{array}{l}24,8 \pm 2 \\
83\end{array}$ & $\begin{array}{l}24,7 \pm 2891 \\
P=0,42 T=0 \\
831\end{array}$ & $25.78 \pm 12.6$ & $\begin{array}{l}14.1 \pm 7,7 \\
(p=0.002) \\
T=0,83\end{array}$ & $84,87 \pm 7.02$ & $\begin{array}{l}9,27 \pm 3,77 \\
(p=0.0189) \\
T=-2,7\end{array}$ & $\begin{array}{l}18,2 \pm 1 \\
98\end{array}$ & $\begin{array}{l}14,2 \pm 2,7 \\
(p=0,002) \\
T=4,92\end{array}$ \\
\hline $\begin{array}{l}\text { NON AD } \\
\text { (5) }\end{array}$ & $\begin{array}{l}3 \mathrm{~F}, 2 \mathrm{M} \\
(40 \%)\end{array}$ & $\begin{array}{l}53 \\
2 \pm 7,7\end{array}$ & $\begin{array}{l}25,3 \pm 2 \\
7\end{array}$ & $\begin{array}{l}26,3 \pm 3,3 \\
P=0,07 \\
T=-2,45\end{array}$ & $31.460 \pm 12.6$ & $\begin{array}{l}32.90 \pm 12.8 \\
(p=0.4065) \\
T=-0,927\end{array}$ & $83,9 \pm 9$ & $\begin{array}{l}82 \pm 9.4 \\
(p=0.29) \\
T=1\end{array}$ & $\begin{array}{l}18,8 \pm 1 \\
1\end{array}$ & $\begin{array}{l}19,4 \pm 1,95 \\
(p=0.208) \\
T=-1,5\end{array}$ \\
\hline
\end{tabular}

Age years, $M$ male, $F$ female, BMI BODY MASS INDEX, AHI APNEA HIPOAPNEA INDEX, O2 Min Minimal o2 adherence, ESS Epworth Sleepiness scale, $A D H$ ADHERENCE

choice, it presents a reasonable alternative. For patients who are unable to attend weekly sessions with a myofunctional therapist, the App provides a practical substitute.

We have to point out that some patients have a small variation in their results and that could be considered as a night-to-night intra-individual variability due the small sample of this study. This could generate a bias that should be corrected in future investigations with larger samples.

In our series, patients 10,11,13,14 and 15 showed a significant improvement in their IAH. We are working with IOPI(Adams et al., n.d.) as a tool to measure the tongue strength prior to use the App. These patients present the lowest values of all the group. We hypothesize that hypotonia is the main phenotype of their OSAHS as suggested by Carberry et al.(Carberry et al. 2018). In our most recent manuscript, we showed a correlation between low IOPI tongue scores and the presence of tongue collapse showed in the DISE of severe OSA patients (O'Connor Reina n.f.). We believe that patient with lowest IOPI scores are the best candidates for our App. Under our experience, improving IOPI scores obtained using our App is the best guideline that exercises are being done correctly. We are performing a clinical trial to assure this matter.

Despite our small sample it is significant the age difference between the two groups, we think it could be associated with the prevalence of the use of smartphones between young people.

Adherence to the described treatment is reasonable and can be compared to another reported

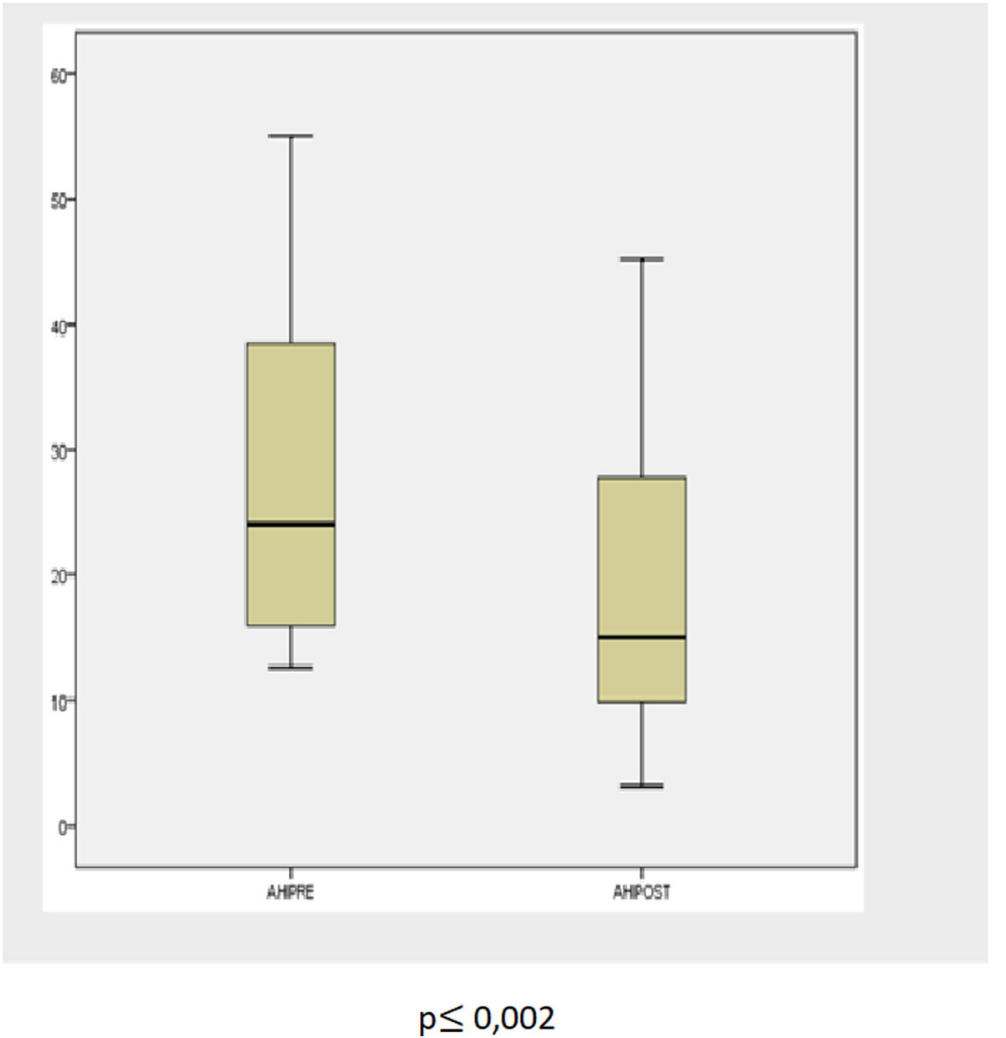

Fig. 5 Box plot showing statistical significant differences between study and control groups 
series.(Hevener and Hevener 2016) There may be selection bias because other therapeutic options have failed for these patients. We are conducting now a study with general population of patients with severe OSAHS. This treatment also may increase compliance with other established treatments as has been reported previously for MT.(Diaféria et al. 2017) A limitation of this study is that the patient must have a smartphone.

The future treatment and diagnosis of this disease will be based on the use of Apps(Lim and Pack 2017), as shown by Kim et al. (2019) We currently recommend that our patients use the App simultaneously with other daily diagnosis tools(Camacho et al. 2015b) to provide objective feedback of their progress in their activity. One of the great advantages of this App is the possibility of contacting a therapist who can observe the daily evolution of the patients' exercises. This provides substantial information for therapeutic decisions based on the evolution of their disease. These exercises are based in those presented in the literature and adapted to interact with the phone(KCC 2009). The duration of the study and the frequency of exercises are based in other myofunctional studies (Guimarães et al. 2009; Ieto et al. 2015; Nemati et al. 2015). We understand there is not enough evidence to validate any exercise due the reduced literature about this matter(Camacho et al. 2015a).

One of the negative points of using MT to treat sleepdisordered breathing is that patients need to perform the exercises beyond a 3-month period and if they stop the exercises, AHI might return to previous levels.(Guimarães et al. 2009) Daily CPAP or MAD treatments do not alter the AHI of patients with OSAHS if the patient is not adherent to the treatment, and similarly AHI might return to previous levels if therapy is stopped. In our present series, patients did not show any difficulty changing their entire nights' treatment for $20 \mathrm{~min}$ a day of oropharyngeal exercises. Their feedback is that they slept much better when they use the App. We have seen in these patients that improvement in their AHI increased if they maintain exercises beyond 3 months. Further investigations are needed to support this point.

There are serious concerns for ethical, security, privacy, and connectivity issues surrounding Apps that promise to cure diseases(De La Vega and Miró 2014) in the mHealth realm. This App is focused on helping patients to perform exercises with their oropharyngeal muscles with the aim of increasing their tone. This study is anecdotal compared with the evidence existing for other therapeutic options. The present study is preliminary, but quantitative improvement of OSAHS may be supported with further reports on the use of this App. It is difficult to present an App as a new therapeutic option for OSAHS, but considering the prevalence of noncompliance with standard treatments,(Burks et al. 2016) we consider this report worthwhile.

Reasons for rejection of the App included problems with the temporomandibular joint (1 case), irritation of the tongue (1 case), and fatigue (3 cases). We do not recommend this App in patients with temporomandibular joint disorders because they can worsen with the exercises. On the other side, we always recommend to use an hypoallergenic plastic wrap to cover the screen before contacting with the tongue in order to avoid adverse reactions.

Goswami et al.(Goswami et al. 2019) reported recently a randomized controlled trial with snorer patients using a smartphone-based delivery with oropharyngeal exercises created during vocalization. They excluded patients with OSAHS. They present significant reduction in snoring and ESS after 8 weeks of using the device.

We have recently reported(O'Connor Reina et al. 2019) the first case of a OSAHS patient with a floppy trap door epiglottis cured using this App. His initial ESS was 22, AHI was 31.2 and minimal $\mathrm{O}_{2}$ saturation was 81.3\%. After 90 sessions with the App, AHI was reduced to 17.2 , minimal $\mathrm{O}_{2}$ saturation improved to $85.1 \%$, and his Epworth sleepiness scale improved to 15 . The floppy epiglottis disappeared as was confirmed by final DISE. Being the first case reported of a floppy epiglottis Apparently cured using an MT-based smartphone App, we do not have a clear scientific reason to explain our finding. We understand that MT increases tone in the muscles of the tongue, also achieving a reduction in its fat content.

These changes are supposed to "tense" the glossoepiglottic folds, and this tension might act like suspenders that prevent the collapse of the epiglottis. Further studies are needed to support this suggestion.

\section{Conclusion}

To our knowledge, this is the first study reported where an mHealth App based on MT could be by itself a therapeutic option for selected patients with OSAHS. Randomized-controlled trials and cost-effectiveness investigations are needed to support this concept.

\section{Abbreviation \\ ADH: adherence; AHI: apnea-hypopnea index; App: Application; BMI: Body mass index; CE: European Community; CPAP: Continuous Airway pressure; ESS: Epworth Sleepiness Scale; IOPI: Iowa Oral Performance Instrument: MAD: Mandibular Advanced Device; MT: myofunctional therapy; $\mathrm{O}_{2 \mathrm{MIN}}$ : oxygen minimal saturation; OSAHS: obstructive sleep apnea/hypopnea syndrome; UE: European Union}

\section{Acknowledgements}

Not Applicable

Ethical approval and consent to partcipate

AWGAPN-2019-01. All procedures performed in studies involving human participants were in accordance with the ethical standards of the 
institutional and/or national research committee and with the 1964 Helsink declaration and its later amendments or comparable ethical standards. Informed consent: Informed consent was obtained from all individual participants included in the study.

\section{Authors' contributions}

Dr. Carlos O'Connor Reina, Dr. Peter Baptista Jardin and Dr. Guillermo Plaza had full access to all the data in the study and takes responsibility for the integrity of the data and the accuracy of the data analysis.

Dra Garcia Iriarte, Dr. De Vicente and Dr. Casado special contribution in data collection and writing and editing assistance.

Dr. Ignacio-Garcia assisted in the translation and statistics.

Mr. Agustin Rodriguez assessed in the technical issues of the App,

\section{Funding}

This study has no funds.

\section{Availability of data and materials}

The raw data on which the results in the current study are based may be requested from the corresponding author upon reasonable request.

\section{Consent for publication}

Not applicable

\section{Competing interests}

Dr. C O'Connor-Reina and Dra M Garcia-Iriarte are the otorhinolaryngologists designers of this App and Mr. A. Rodriguez-Reina is the informatic engineer who develop the App.

G. Plaza declares no conflict of interest.

J. Ignacio-Garcia declares no conflict of interest.

P. Baptista Jardin declares no conflicto of interest.

JC Casado-Morente declares no conflict of interest.

E. De Vicente Gonzalez declares no conflict of interest.

\section{Author details}

${ }^{1}$ Cohead Department Otorhinolaryngology, Hospital Quiron Salud Marbella, Avenida Severo Ochoa 22, 29603 Marbella, Spain. ${ }^{2}$ Cohead Department of Otorhinolaryngology, Hospital Quiron Salud Campo de Gibraltar, Cádiz, Spain. ${ }^{3}$ Head Otorhinolaryngology Department, Hospital Sanitas la Zarzuela, Madrid, Spain. ${ }^{4}$ Head Department Otorhinolaryngology, Hospital Universitario Fuenlabrada, Fuenlabrada, Spain. ${ }^{5}$ Head Neumology Department, Hospital Quiron Salud Marbella, Marbella, Spain. ${ }^{6}$ Head Neumology Department, Hospital Quiron Salud Campo de Gibraltar, Cádiz, Spain.

${ }^{7}$ Otorhinolaryngology Department, Clinica Universitaria de Navarra, Pamplona, Spain. ${ }^{8}$ Otorhinolaryngology Department, Hospital la Merced Osuna Sevilla, Sevilla, Spain. ${ }^{9}$ Department Otorhinolaryngology, Hospital Universitario Miguel Servet, Zaragoza, Spain. ${ }^{10}$ Department Informatic \& Engineering, Apnea Bye S.L, Sevilla, Spain.

Received: 1 July 2019 Accepted: 9 December 2019

Published online: 05 February 2020

\section{References}

Adams, V, Mathisen, B, Baines, S et al. A systematic review and meta-analysis of measurements of tongue and hand strength and endurance using the lowa Oral Performance Instrument (IOPI).

American Academy of Sleep Medicine. The AASM manual for the scoring of sleep and associated events: rules, terminology, and technical specifications. Westchester: American Academy of Sleep Medicine; 2007.

Andrews S, Ellis DA, Shaw H, Piwek L. Beyond self-report: tools to compare estimated and real-world smartphone use. PLoS One. 2015;10(10):e0139004. https://doi.org/10.1371/journal.pone.0139004.

Burks SV, Anderson JE, Bombyk M, et al. Nonadherence with employer-mandated sleep apnea treatment and increased risk of serious truck crashes. Sleep. 2016;39(5):967-75. https://doi.org/10.5665/sleep.5734.

Camacho M, Certal V, Abdullatif J, et al. Myofunctional therapy to treat obstructive sleep apnea: a systematic review and meta-analysis. Sleep. 2015a; 38(5):669-75. https://doi.org/10.5665/sleep.4652.

Camacho M, Robertson M, Abdullatif J, et al. Smartphone apps for snoring. J Laryngol Otol. 2015b;129(10):974-9. https://doi.org/10.1017/ S0022215115001978.
Carberry JC, Amatoury J, Eckert DJ. Personalized management approach for OSAHS. Chest. 2018;153(3):744-55. https://doi.org/10.1016/j.chest.2017.06.011.

De La Vega R, Miró J. mHealth: a strategic field without a solid scientific soul. A systematic review of pain-related apps. PLoS One. 2014;9(7):e101312. https:// doi.org/10.1371/journal.pone.0101312.

Diaféria G, Santos-Silva R, Truksinas E, et al. Myofunctional therapy improves adherence to continuous positive airway pressure treatment. Sleep Breath. 2017;21(2):387-95. https://doi.org/10.1007/s11325-016-1429-6.

Dotan Y, Pillar G, Schwartz AR, Oliven A. Asynchrony of lingual muscle recruitment during sleep in obstructive sleep apnea. J Appl Physiol. 2015; 118(12):1516-24. https://doi.org/10.1152/japplphysiol.00937.2014.

Goswami U, Black A, Krohn B, et al. Smartphone-based delivery of oropharyngeal exercises for treatment of snoring: a randomized controlled trial. Sleep Breath. 2019;23:243. https://doi.org/10.1007/s11325-018-1690-y.

Guimarães KC, Drager LF, Genta PR, Marcondes BF, Lorenzi-Filhoy G. Effects of oropharyngeal exercises on patients with moderate obstructive sleep apnea syndrome. Am J Respir Crit Care Med. 2009;179(10):962-6. https://doi.org/10. 1164/rccm.200806-9810C.

Hevener B, Hevener W. Continuous positive airway pressure therapy for obstructive sleep apnea: maximizing adherence including using novel information technology-based systems. Sleep Med Clin. 2016;11(3):323-9. https://doi.org/10.1016/j.jsmc.2016.04.004.

leto $\mathrm{V}$, Kayamori F, Montes Ml, et al. Effects of oropharyngeal exercises on snoring: a randomized trial. Chest. 2015; https://doi.org/10.1378/chest.142953.

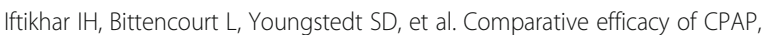
MADs, exercise-training, and dietary weight loss for sleep apnea: a network meta-analysis. Sleep Med. 2017 Feb;30:7-14. https://doi.org/10.1016/j.sleep. 2016.06.001.

Isetta V, Torres M, González K, et al. A new mHealth application to support treatment of sleep apnoea patients. J Telemed Telecare. 2017 Jan;23(1):14-8. https://doi.org/10.1177/1357633X15621848.

Guimaraes KCC. Apneia e Ronco. Tratamiento Miofuncional Orofacial:tratamento miofuncional orofacial. In: Pulso, ed. San Jose dos Campos; 2009, pp 53-63.

Kim JW, Ryu B, Cho S, et al. Impact of personal health records and wearables on health outcomes and patient response: three-arm randomized controlled trial. JMIR Mhealth Uhealth. 2019;7(1):e12070. https://doi.org/10.2196/12070.

Korhan I, Gode S, Midilli R, Basoglu OK. The influence of the lateral pharyngeal wall anatomy on snoring and sleep apnoea. J Pak Med Assoc. 2015;65(2): 125-30.

Lim DC, Pack Al. Obstructive sleep apnea: update and future. Annu Rev MedAnnu Rev Med. 2017;68:99-112. https://doi.org/10.1146/annurev-med042915-102623.

Mendes F, Marone S, Duarte B, Arenas A. Epidemiologic profile of patients with snoring and obstructive sleep apnea in a university hospital. Int Arch Otorhinolaryngol. 2014;18(02):142-5. https://doi.org/10.1055/s-0033-1359309.

Nemati S, Gerami H, Soltanipour S, Saberi A, Moghadam SK, Setva F. The effects of oropharyngeal-lingual exercises in patients with primary snoring. Eur Arch Otorhinolaryngol. 2015;272(4):1027-31. https://doi.org/10.1007/s00405-0143382-y.

O'Connor Reina C, García Iriarte MT, Casado-Morente JC, et al. New app "Apnea Bye" increases adherence in myofunctional therapy to treat sleep disorder breathing. Otolaryngol Neck Surg. 2018;159(1_suppl):P326-7. https://doi.org/ 10.1177/0194599818787193j.

O'Connor Reina C, Plaza Mayor G, Ignacio-Garcia J, et al. Floppy closing door epiglottis treated successfully with an Mhealth application based on myofunctional therapy: a case report. Case Rep Otolaryngol. 2019;2019: 4157898. https://doi.org/10.1155/2019/4157898.

O'Connor Reina C, Plaza G, Garcia Iriarte MT, et al. Tongue peak pressure: a tool to aid in the identification of obstruction sites in patients with obstructive sleep apnea/hypopnea syndrome. Sleep Breath. https://doi.org/10.1007/ s11325-019-01952-x. In Press

Vogel MME, Combs SE, Kessel KA. mHealth and application technology supporting clinical trials: Today's limitations and future perspective of smartRCTs. Front Oncol. 2017;7:37. https://doi.org/10.3389/fonc.2017.0003.

\section{Publisher's Note}

Springer Nature remains neutral with regard to jurisdictional claims in published maps and institutional affiliations. 